\title{
TENDÊNCIAS INOVADORAS DE GESTÃO NOS GOVERNOS SUBNACIONAIS BRASILEIROS
}

\author{
Tendencias Innovadoras de Gestión en los Gobiernos Subnacionales Brasileños \\ Innovative Management Trends in the Brazilian Subnational Governments
}

\begin{abstract}
RESUMO
0 propósito deste trabalho é analisar em que medida as políticas públicas e de gestão dos governos subnacionais brasileiros estão alinhadas com as tendências de inovação na atual era pós-nova gestão pública. Para tanto, o artigo desenvolve uma abrangente análise de conteúdo dos trabalhos apresentados nas nove edições do congresso do Consad focados em iniciativas dos Estados e municípios, a partir da análise de um protocolo de tendências de gestão identificadas na literatura. Os resultados da pesquisa, em geral, também complementados com referências a casos de sucesso, sinalizam que os governos subnacionais no Brasil estão convergentes com as práticas mais contemporâneas. Além disso, a maioria das iniciativas incorpora mais de uma tendência, o que confirma a perspectiva de que as políticas inovadoras advêm da implementação de diferentes princípios e diretrizes.
\end{abstract}

PALAVRAS-CHAVE: reformas do Estado, pós-nova gestão pública, inovação, governos estaduais, prefeituras.

\section{Pedro Luiz Costa Cavalcante ${ }^{1}$}

pedro.cavalcante@ipea.gov.br

ORCID: 0000-0001-7635-695X

${ }^{1}$ PEA, Brasil

Submetido 24.05.2019. Aprovado 18.11.2019

Avaliado pelo processo de double blind review

DOI: http://dx.doi.org/10.12660/cgpc.v24n79.79294 


\section{ABSTRACT}

The paper's main go is to analyze in which extent the public policies and management of the Brazilian subnational governments are in line with the innovation trends in the current Post New Public Management Era. To do so, the inquiry develops a comprehensive content analysis of articles presented in nine editions of the Consad's conference focused on initiatives of states and municipalities, based on a protocol of management trends identified in the literature. The research results, in general, in addition with references of successful cases, indicate that the subnational governments in Brazil are convergent with the most contemporary practices. Besides, most of the initiatives incorporate more than one trend, confirming the premise that innovative policies come from the implementation of different principles and guidelines.

KEYWORDS: State reform, post new public management, innovation, state governments, local governments.

\section{RESUMEN}

El propósito de este trabajo es analizar en qué medida las políticas públicas y de gestión de los gobiernos subnacionales brasileños están alineadas con las tendencias de innovacion en la actual Era Post Nueva Gestión Pública. Para tanto, el artículo desarrolla un amplio análisis de contenido de trabajos presentados en las nueve ediciones del Congreso del Consad enfocados en iniciativas de los estados y municipios, a partir de un protocolo de tendencias de gestión identificadas en la literatura. Los resultados de la investigación, en general, e también complèmentados con referencias a casos de éxito, señalan que los gobiernos subnacionales en Brasil están bastante alineados con las prácticas más contemporáneas. Además, la mayoría de las iniciativas incorporan más de una tendencia, lo que confirma la perspectiva de que las políticas innovadoras provienen de la aplicación de diferentes principios y directrices.

PALABRAS CLAVE: reforma del Estado, post nueva gestión pública, innovación, gobiernos estaduales, ayuntamientos.

\section{INTRODUÇÃO}

As intensas e constantes transformações pelas quais o setor público vem passando nas últimas décadas passaram a exigir não apenas amplas reflexões sobre o papel e as responsabilidades estatais, como também demandam que a administração pública formule e implemente políticas e serviços públicos mais efetivos, eficientes e em processos interativos com a sociedade e a iniciativa privada.

As administrações públicas estaduais e locais em todo o mundo há décadas empreendem reformas, isto é, "conjunto de mudanças deliberadas nas estruturas e processos das organizações do setor público com o objetivo de fazer com que elas funcionem (em algum sentido) melhor" (Pollit \& Buckaert, 2011, p. 2). A despeito do fato de que a maioria desses esforços não tenham gera- do os resultados planejados (Alverga, 2003; Christensen \& Lægreid, 2007; Pollit \& Buckaert, 2011), não se pode ignorar que tais iniciativas almejaram desenvolver capacidades estatais, melhorar o desempenho da gestão e, por conseguinte, modificar a configuração e o funcionamento do setor público nas últimas décadas. No entanto, a opção por grandes esforços reformistas tem caído em desuso, devido ao alto custo transacional que as mudanças mais radicais tendem a gerar. Os obstáculos e as resistências inerentes a processos reformistas, normalmente, trazem resultados aquém do planejado (Pollit \& Buckaert, 2011).

Logo, o caminho dos governos tem sido por melhorias pequenas e constantes, denominadas em inglês de micro-improvements (Pollitt \& Bouckaert; 2011; Greve, Lægreid, \& Rykkja; 2016). Na prática, essas iniciativas podem ser consideradas como inovações, 


\section{TENDÊNCIAS INOVADORAS DE GESTÃO NOS GOVERNOS SUBNACIONAIS BRASILEIROS}

uma vez que consistem na geração e implementação de novas ideias com vistas a criar valor para a sociedade, sejam elas com foco interno ou externo à administração pública (Osborne \& Brown, 2005; Comissão Europeia, 2013). Nesse sentido, a questão que surge é: que tendências, em termos de princípios e diretrizes, são observadas na administração pública no Brasil, em especial nos governos estaduais e municipais, após a hegemonia de reformas pautadas na Nova Gestão Pública (NGP)? O propósito deste artigo é contribuir para esse debate e sobretudo analisar como as políticas públicas e de gestão dos governos subnacionais brasileiros estão alinhadas às tendências internacionais na administração pública.

Para tanto, primeiro, essas tendências pós-NGP (princípios e diretrizes), extraídas de uma ampla revisão de literatura nacional e internacional, são discernidas. A partir de um protocolo criado dessas tendências, analisam-se as ações governamentais dos Estados e municípios brasileiros, apresentados nas nove últimas edições do Congresso do Conselho Nacional de Secretários de Estado da Administração (Consad) e discutem-se as relações com os princípios e as diretrizes no pós-NGP. De modo adicional, são utilizadas referências a casos de sucesso.

Além desta introdução, o artigo traz uma objetiva contextualização do debate acerca das mudanças nas últimas décadas da gestão subnacional brasileira de modo a situar a literatura acerca dessa discussão. Em seguida, apresenta a fundamentação teórica, metodologia e as análises empíricas. Por fim, algumas conclusões e a agenda futura de pesquisa são apresentadas.
Gestão Pública Subnacional no Brasil: mudanças nas últimas décadas

Almeja-se contextualizar de forma breve, com base na literatura brasileira, a evolução do debate sobre o funcionamento da administração pública nos Estados e municípios.

No caso nacional, esses processos reformistas foram muito influenciados pelas propostas presentes no Plano Diretor de Reforma do Estado (PDRAE) de 1995, fundamentado em princípios da NGP ou New Public Management (NPM) (Abrucio, 2007). Durante o primeiro mandato do governo de Fernando Henrique Cardoso, foi criada uma pasta específica para liderar a reforma administrativa (Ministério da Administração Federal da Reforma do Estado - Mare). Cardoso nomeou um ex-ministro da Economia para administrar o programa, Bresser Pereira, que se baseou nas experiências anglo-saxônicas para propor que as regras da gestão pública fossem mais flexíveis como estratégia de aprimorar o desempenho do setor público brasileiro. O programa visava a:

- Aumentar a governança do Estado, entendida como sua capacidade administrativa para governar eficaz e eficientemente, voltando os serviços públicos aos cidadãos;

- Limitar o papel do Estado a funções essenciais;

- Descentralizar quase todas as políticas para os Estados e municípios;

- Transferir parte da União para as políticas regionais dos Estados, a fim de promover a cooperação entre eles.

Como resultado, o PDRAE obteve relativo êxito na criação de agências reguladoras; 
promoção da cultura de avaliação, especialmente de desempenho; descentralização de políticas sociais; e algumas inovações ligadas ao planejamento e gerenciamento orçamentário (Gaetani, 2003; Da Costa, 2008; Abrucio, 2007). No entanto, a introdução de instrumentos mais audaciosos de gestão de pessoas no serviço público e o projeto de publicização, ou seja, a transferência para a sociedade da condução de parte da política social, no formato de organizações sociais, não se concretizou plenamente na esfera federal. Apesar disso, a estratégia de publicização passou a ser incorporada no nível subnacional, em algumas áreas, como educação e saúde (Bresser Pereira, 2002; Bresser Pereira \& Pacheco, 2005; Abrúcio 2007; Brulon, Ohayon, \& Rosenberg, 2012). De acordo com Abrucio (2007), existiam cerca de setenta (70) organizações sociais (OS) e sua variação um pouco mais recente, organizações da sociedade civil de interesse público (Oscip), nos governos estaduais, até o período de análise.

Ainda no âmbito subnacional, no período entre 1996 e 2004, vale menção ao Programa de Gestão Pública e Cidadania que premiou e ajudou a disseminar milhares de iniciativas inovadoras nos governos locais brasileiros (Jacobi \& Pinho, 2006). Nesse esforço, aspectos de cocriação, como a participação social e serviços de cogestão com outras organizações públicas ou privadas, foram determinantes para inovações florescerem (Spink, 2006). Do mesmo modo, foram identificados como fatores fundamentais para o sucesso da cooperação intermunicipal a inclusão de novos atores no policymaking, as parcerias com as ONGs e o envolvimento da comunidade (Fahah, 2006).
Com a chegada do Partido dos Trabalhadores (PT) à Presidência da República, em 2003, o debate sobre reformas administrativas perde fôlego, ao menos no discurso oficial. Isso não significa dizer que o governo federal virou de costas para o que ocorria no debate e nas práticas contemporâneas de gestão pública (Cavalcante \& Camões, 2017). Nesse período, algumas iniciativas dos governos anteriores continuaram sendo adotadas, como a intensificação da descentralização da política social para os governos locais, algumas privatizações dos serviços públicos, reforma da previdência em 2003, bem como o foco em desempenho e resultados. $O$ governo petista também iniciou um processo de restruturação da burocracia federal, baseado no aumento quantitativo de pessoal e na diversificação de carreiras, com forte discurso de fortalecimento do Estado (Cavalcante \& Carvalho, 2017). Além disso, as políticas de ampliação da participação social, a transparência e a avaliação/monitoramento de políticas públicas foram valorizadas nos mandatos do PT.

Em relação aos governos subnacionais, apesar das raras publicações acadêmicas acerca do funcionamento dos governos estaduais e municipais no Brasil, as políticas que mais se destacaram nos últimos anos foram justamente os programas de apoio à gestão nos Estados coordenados pelo Executivo federal e executados pelo Banco Interamericano de Desenvolvimento (BID). Se durante o governo $\mathrm{FHC}$ o foco foi o auxílio à área financeira, mediante o Programa Nacional de Apoio à Administração Fiscal para os Estados Brasileiros (PNAFE), nos governos do PT, a prioridade transferiu-se para o suporte à gestão pública subnacional com duas ações basilares: o Programa Nacional de Apoio à Moder- 


\section{TENDÊNCIAS INOVADORAS DE GESTÃO NOS GOVERNOS SUBNACIONAIS BRASILEIROS}

nização da Gestão e do Planejamento dos Estados e do Distrito Federal (PNAGE) e o Programa de Modernização do Controle Externo dos Estados e Municípios Brasileiros (Promoex) (Abrucio, 2005).

O diagnóstico até o início dessas iniciativas em 2005 era que as administrações públicas subnacionais no Brasil seriam caracterizadas por falhas na organização de suas informações básicas e da memória administrativa, na gestão dos recursos humanos, na articulação entre as várias partes do sistema de planejamento, na adoção de um enfoque mais intersetorial e, ainda, na adoção de melhores mecanismos de governança democrática (Abrucio, 2005). Em relação ao controle externo, era notória a fragilidade dos órgãos responsáveis, sobretudo, no tocante à estruturação de um efetivo sistema de accountability.

A despeito da ausência de uma avaliação efetiva desses programas, prevalece certo consenso sobre os avanços em termos de melhoria da gestão nas décadas de $90 \mathrm{e}$ 2000. No período, os governos estaduais e, principalmente, os municipais introduziram novidades em termos de participação social e, no caso dos Estados, a expansão dos centros de atendimento integrado (Abrucio, 2007; Marini, 2005). Além do fortalecimento do planejamento na figura do Plano Plurianual (Abrucio, 2007; Lotufo \& Miranda, 2007) e algumas experiências de ampliação de accountability por parte da administração pública estadual (Corrêa, 2007).

Mais recentemente, o campo de estudo vem focando as pesquisas mais em experiências subnacionais específicas e menos em análises de reforma, assim como a literatura in- ternacional, conforme veremos na próxima seção.

No âmbito do relacionamento Estado-sociedade, vale menção ao livro Por uma Nova Gestão Pública, no qual Paula (2005) argumenta que, após o PDRAE, surgiram reinvenções institucionais para adequarem-se à demanda por participação social, em um contexto institucional ampliado de gestão pública democrática. Para a autora, o plano deu prioridade às dimensões econômico-financeira e institucional-administrativa, com pouca ênfase na dimensão sociopolítica. Do lado acadêmico, é perceptível, todavia, uma intensificação nas abordagens sobre inovações institucionais de caráter participativo. Nesse sentido, Paula e Keinert (2016) defendem o crescimento e a relevância dessas iniciativas, tais como conselhos gestores, orçamento participativo, audiências públicas, fóruns e conferências, na prática e no estudo de administração pública.

As abordagens sobre accountability nos governos subnacionais também vêm se destacando. Nessa direção, Raupp e Pinho (2016) analisam os portais públicos eletrônicos em municípios catarinenses e concluem que os seus efeitos são variados, uma vez que, embora promovam condições para o processo de prestação de contas e transparência, nota-se, por outro lado, baixa capacidade de participação/interação com os cidadãos. Com foco no âmbito estadual, Raupp, Pinho e Bruni (2017) comparam o grau de accountability de duas unidades hospitalares, uma da administração direta e outra em regime de parceria público-privada. Os resultados indicam que, embora o segundo modelo apresente avanços na direção de accountability de resultado, prevalecem carências na 
promoção da transparência pública.

Finalmente, cabe destacar uma dimensão crucial para a compreensão da gestão pública em contexto democrático e federativo como o brasileiro: o relacionamento intergovernamental. Dessa forma, os esforços de construção de uma efetiva governança federativa surtiram bons resultados nas áreas da saúde e educação, enquanto que, no âmbito do controle, o fortalecimento é mais restrito à esfera federal (Raupp \& Pinho, 2011). Não obstante, o papel do governo nacional ainda é central, sobretudo em relação às administrações locais. De acordo com Grin e Abrucio (2016), embora os municípios tenham recebido mais funções pós-Constituição de 88 , ainda predominam gargalos nos seus recursos e capacidades de modo que é clara a assimetria entre eles e a esfera federal nesses quesitos.

\section{As Tendências da Era Pós-Nova Gestão Pú- blica}

O objetivo da seção é apresentar as tendências contemporâneas da administração pública que permeiam as políticas públicas e de gestão com base em uma revisão de literatura que analisa a produção acadêmica recente e gera parâmetros analíticos para a compreensão acerca do funcionamento do Estado atual (Cavalcante, 2017).

Esse levantamento bibliográfico foi conduzido com os seguintes critérios: i) recorte temporal: os estudos foram restritos àqueles publicados no período de janeiro de 2007 a março de 2017; ii) status da publicação: foram considerados livros publicados por editoras no campo de administração pública em que as bases para as pesquisas dos livros foram o sítio eletrônico da Coordenação de Aperfeiçoamento de Pessoal de Nível Superior (Capes) e o Google books, como também revistas acadêmicas internacionais (Journal of Public Administration Research and Theory; Public Administration Review; Governance; International Public Management Journal; e Public Administration) e nacionais (Revista de Administração Contemporânea (RAC); Revista de Administração da USP (RAUSP); e Revista de Administração Pública (RAP) com maiores fatores de impacto na área; iii) estratégia de pesquisa: os descritores procurados foram "new public management"; "public service reform"; "post new public management"; "administrative reform" e "public management reform", bem como suas versões em português. Os descritores foram pesquisados nos títulos, palavras-chave e resumos dos artigos e livros (Cavalcante, 2017).

Antes de apresentar as tendências, cabe ponderar alguns pontos que vêm convergindo na literatura. O primeiro deles enfatiza mais a visão de gradualismo e continuidade pós-NGP do que propriamente de superação ao modelo anterior. Christensen e Lægreid (2007) defendem que a NGP possui um efeito restritivo sobre as reformas seguintes. As propostas de mudanças tendem sua implementação a partir do que já foi adotado, seja para incluir algo novo ou para solucionar problemas ainda não resolvidos. Nessa linha, Greve et al. (2016) argumentam que as novas tendências não significam que as características da NGP estejam desaparecendo. Como exemplos, a gestão por desempenho e o foco nos resultados/impactos, componentes centrais na NGP, continuam em voga na administração pública, contudo perderam a essência de novidade. Os autores sugerem 
que a melhor forma é utilizar uma lente institucional histórica, que se fundamenta em uma abordagem de "camadas" institucionais. Em outras palavras, as "soluções" são desenvolvidas gradualmente e cumulativamente ao longo do tempo, de forma que os princípios e as diretrizes continuam coexistindo nas práticas administrativas.

Compreender essas transformações, sem dúvida, não é um exercício trivial, porém é consenso que ocorreram mudanças significativas na forma como o setor público vem funcionando nas últimas décadas, que difere muito dos princípios e das diretrizes de gestão propagados no fim dos anos 70 e começo da década de 80.

É justamente esse processo difuso e ambíguo que faz com que muitas das características da NGP acabem sendo incorporadas na prática cotidiana da administração pública, no que convém denominar de pós-NGP (Greve et al., 2016). Com isso, as estratégias reformistas abrangentes vêm sendo substituídas pelo enfoque governamental por me-
Ihorias pequenas e constantes, o que Pollitt e Bouckaert (2011) denominam de micro-improvements. Essas mudanças incrementais, mesmo em pequena escala, são resultantes do processo de criação ou adoção de novas ideias que geram valor à sociedade, ou seja, similar ao conceito de inovação no setor público (Osborne \& Brown, 2005; Comissão Europeia, 2013).

Nessa linha, o Quadro 1 sintetiza as tendências de princípios e diretrizes contemporâneos de gestão pública caracterizadas como parte do pós-NGP, com seus respectivos significados e as palavras-chave usadas como protocolo para identificação de suas presenças nos trabalhos das nove edições do congresso do Consad. Consideram as tendências de gestão sob duas dimensões: princípios e diretrizes. A primeira significa a razão que fundamenta a ação, enquanto a diretriz de gestão envolve a orientação ou indicação de um caminho a seguir. O ordenamento segue a frequência de ocorrência nos artigos e livros mapeados nessa revisão de literatura (Cavalcante, 2017). 
Pedro Luiz Costa Cavalcante

\section{Quadro 1.Tendências do Pós-Nova Gestão Pública}

\begin{tabular}{|c|c|c|}
\hline Princípios e Diretrizes & Significados & Descritores \\
\hline Colaboração e parcerias & $\begin{array}{l}\text { Processos colaborativos e de parce- } \\
\text { rias de formas variadas, dentro do } \\
\text { setor público, com a iniciativa privada } \\
\text { e o terceiro setor. }\end{array}$ & $\begin{array}{l}\text { Colaboração, parceria, parceiro (a), } \\
\text { cooperação, coparticipação, cocria- } \\
\text { ção, coprodução. }\end{array}$ \\
\hline Redes & $\begin{array}{l}\text { Atuação em redes na provisão de } \\
\text { serviços públicos (formulação; imple- } \\
\text { mentação; e controle). }\end{array}$ & $\begin{array}{l}\text { Redes, gestão de redes, governan- } \\
\text { ça em redes, network. }\end{array}$ \\
\hline $\begin{array}{l}\text { Visão integrada e holística da } \\
\text { gestão pública }\end{array}$ & $\begin{array}{l}\text { Premissa de serviços públicos inte- } \\
\text { grados e perspectiva administrativa } \\
\text { como um todo -- coesa e coerente } \\
\text { (não fragmentada ou competitiva) } \\
\text { ideia de joined-up government e who- } \\
\text { le of government. }\end{array}$ & $\begin{array}{l}\text { integração, integralidade, transver- } \\
\text { salidade, intersetorialidade, coesão } \\
\text { governamental, coerência gover- } \\
\text { namental, joined-up government; } \\
\text { whole of government; governo como } \\
\text { um todo. }\end{array}$ \\
\hline $\begin{array}{l}\text { Accountability e responsivida- } \\
\text { de }\end{array}$ & $\begin{array}{l}\text { Processos de ampliação da prestação } \\
\text { de contas e capacidade de respostas } \\
\text { da administração pública à sociedade. }\end{array}$ & $\begin{array}{l}\text { accountability, responsividade, pres- } \\
\text { tação, contas, transparência, res- } \\
\text { ponsabilização. }\end{array}$ \\
\hline Participação e engajamento & $\begin{array}{l}\text { Ampliação de canais de participação } \\
\text { social no policymaking e fomento ao } \\
\text { envolvimento da sociedade na gestão } \\
\text { pública como valor e fonte de legitimi- } \\
\text { dade. }\end{array}$ & $\begin{array}{l}\text { controle social, participação, enga- } \\
\text { jamento, articulação social, partilha } \\
\text { de poder, democracia participativa, } \\
\text { compartilhamento, envolvimento, } \\
\text { inclusão (em processo decisório). }\end{array}$ \\
\hline Liderança & $\begin{array}{l}\text { Importância do papel do líder (políti- } \\
\text { co; administrativo ou cidadão) na ges- } \\
\text { tão pública, sobretudo em processos } \\
\text { empreendedores. }\end{array}$ & $\begin{array}{l}\text { diretor, chefe, direção, líder, lideran- } \\
\text { ça, dirigência; condução política, } \\
\text { direção estratégica, direção política, } \\
\text { empreendedorismo, direção técnica. }\end{array}$ \\
\hline Coordenação e controle & $\begin{array}{l}\text { Fortalecimento das capacidades de } \\
\text { coordenação e controle da adminis- } \\
\text { tração como forma de gerar coerência } \\
\text { e coesão na prestação de serviços } \\
\text { públicos. }\end{array}$ & $\begin{array}{l}\text { coordenação, controle, gerencia- } \\
\text { mento, direção, comando, supervi- } \\
\text { são, articulação, arranjo, monitora- } \\
\text { mento. }\end{array}$ \\
\hline E-government & $\begin{array}{l}\text { Incorporação frequente do uso de tec- } \\
\text { nologias da informação para aumen- } \\
\text { tar a transparência do setor público, } \\
\text { bem como o acesso e envolvimento } \\
\text { do cidadão com a administração pú- } \\
\text { blica. }\end{array}$ & $\begin{array}{l}\text { TIC; TICS, e-government, e-governo, } \\
\text { tecnologia de informação, governo } \\
\text { digital, governo eletrônico, e-gover- } \\
\text { nance, e-gov, sistema de informa- } \\
\text { ção, transparência. }\end{array}$ \\
\hline $\begin{array}{l}\text { Fortalecimento da burocracia } \\
\text { pública }\end{array}$ & $\begin{array}{l}\text { Profissionalização e valorização do } \\
\text { quadro funcional do Estado com vis- } \\
\text { tas a torná-lo mais eficiente, interdis- } \\
\text { ciplinar e responsivo à sociedade. }\end{array}$ & $\begin{array}{l}\text { curso, treinamento, capacitação, } \\
\text { aperfeiçoamento, profissionalização, } \\
\text { especialização, qualificação, valori- } \\
\text { zação, reconhecimento, empodera- } \\
\text { mento. }\end{array}$ \\
\hline
\end{tabular}

Fonte: Cavalcante (2017). 


\section{TENDÊNCIAS INOVADORAS DE GESTÃO NOS GOVERNOS SUBNACIONAIS BRASILEIROS}

Cavalcante (2017) ressalta que outros princípios e diretrizes, por exemplo, eficiência e qualidade dos serviços públicos, foco no cidadão, dentre outros, são menos recorrentes na literatura do período analisado, o que não significa que não sejam importantes ou que estejam ultrapassados. Eles continuam na agenda pública, embora tenham deixado de ser considerados tendências inovadoras nos debates atuais da gestão pública.

Observa-se ainda a coexistência de vários princípios/diretrizes nos estudos, o que também era esperado, pois a complexidade da administração pública demanda que o setor público funcione atendendo diferentes perspectivas e necessidades. Logo, é natural que eles sejam analisados de forma conjunta; exemplo: pensar na implementação de políticas públicas via redes de políticas públicas, em boa medida, pressupõe a ênfase em processos de colaboração e parcerias nas atividades governamentais. Tal constatação converge com a afirmação de Greve, et al. (2016, p.157) de que "Como a NGP, o pós-NGP pode, até certo ponto, ser visto como uma 'cesta de compras' de diferentes métodos".

Fica claro que muitos desses princípios/diretrizes se aproximam das premissas das últimas reformas pautadas na NGP, como os casos de accountability, participação e engajamento, bem como a utilização de estratégias de TIC para melhorar a gestão. Há convergência, portanto, com a perspectiva de que se trata de um processo marcado mais pela continuidade e gradualismo do que pela ruptura com paradigmas anteriores. Em suma, a amplitude e sobreposição dos princípios/diretrizes reforçam a prevalência de um caráter mais incremental de construção do discurso e da prática do que, propriamente, de revolução no debate.

Por fim, cabe esclarecer que essas tendências mapeadas na literatura no contexto de pós-NGP não são as inovações em si. $\mathrm{Na}$ verdade, os princípios e as diretrizes foram identificados como recorrentes nas práticas internacionalmente adotadas ou nos debates mais atuais de gestão pública. A partir dessas tendências é que as inovações ou micro-improvents se desenvolvem (Pollitt e Bouckaert, 2011; Greve, et al., 2016).

Inovações na Gestão Pública em Estados e Municípios Brasileiros

Essa seção dedica-se a analisar os estudos que abordam as ações governamentais de modo a responder à pergunta da pesquisa: Que tendências são observadas na administração pública no Brasil, em especial nos governos subnacionais, após hegemonia de reformas pautadas na Nova Gestão Pública (NGP)? Primeiramente, o caminho metodológico é detalhado.

\section{METODOLOGIA}

Trata-se de uma pesquisa exploratória que, por essa razão, não visa a explicar o fenômeno da inovação ou de boas práticas de gestão nos Estados e municípios brasileiros, mas sim descrever em que medida esses cases vêm sendo implementados e, principalmente, possíveis alinhamentos com as tendências contemporâneas do pós-NGP. Para tanto, o objeto de análise foram os trabalhos apresentados nas nove últimas edições, entre 2008 e 2016, do Congresso do Conselho Nacional de Secretários de Estado da Administração (Consad). A opção em analisar 
essa produção, que inclui tanto trabalhos técnicos quanto acadêmicos, justifica-se na medida em que este era o maior encontro de gestores e especialistas voltado ao debate sobre administração pública no país e que também serve como um grande repositório de experiências e pesquisas aplicadas de gestão pública, sobretudo no âmbito dos governos subnacionais.

Cabe menção à extinta Premiação do Programa de Gestão Pública e Cidadania (GPC) da Fundação Getúlio Vargas (FGV) e Fundação Ford, que premiava anualmente organizações públicas subnacionais (estaduais, municipais, dos poderes Executivo, Legislativo, Judiciário e das organizações próprias dos povos indígenas) que inovavam em maneiras de prestar serviços públicos. Infelizmente, embora tenha avaliado mais de 8 mil iniciativas, a base está desatualizada, uma vez que o prêmio foi finalizado em 2005. Diante da inexistência desse tipo de premiação, a base do Consad é a alternativa mais plausível para investigar a dinâmica da gestão pública nos níveis estadual e local no país. Nesse contexto, parte-se do pressuposto de que as experiências e os casos discutidos durante os congressos são as fontes do que mais se aproxima de práticas inovadoras disponíveis para análise.

Após uma primeira triagem que excluiu da base os artigos que versavam sobre a esfera federal (516 no total), iniciou-se a pesquisa de 841 trabalhos apresentados nos nove anos analisados, sendo 746 relativos aos governos estaduais e 95 aos governos municipais. Eles foram categorizados por análise de conteúdo com base no protocolo com descritores (palavras-chave) relacionados aos significados das tendências pós-NGP
(Quadro 1). Foram seguidas três etapas: i) construção de categorias (tendências); ii) análise e categorização de cada iniciativa por duas assistentes de pesquisa, separadamente e guiadas pela descrição do protocolo; iii) validação pelo autor em caso de desacordo. Para verificação da presença da tendência, utilizou-se o software de análise qualitativa Atlas TI, essencial para mapeamento, organização e tratamento dos casos. Após a identificação de alguma das palavras-chave, elas eram interpretadas para verificação se, de fato, convergiam com o significado da respectiva tendência. $O$ banco de dados, portanto, é composto de variáveis binárias com 0 (zero) se o princípio/diretriz não é identificado e um (1) no caso de sua presença.

Em seguida, o artigo emprega análises descritivas para discutir os resultados. Ademais, a pesquisa incorpora exemplos de iniciativas tanto dos governos municipais quanto estaduais de forma a dar mais profundidade e materialidade aos achados das abordagens de toda a base de dados. Assim, o trabalho utiliza uma mistura de estratégias qualitativas e quantitativas, necessária diante da amplitude do objetivo de investigação.

\section{RESULTADOS}

Os resultados, em linhas gerais, são bem interessantes. Primeiro, e mais importante, é que os governos subnacionais analisados, a partir das experiências apresentadas no congresso do Consad, vêm implementando políticas públicas e de gestão convergentes com as tendências internacionais. Apesar de notar-se uma variedade na incorporação desses princípios e diretrizes, poucos são os casos que não envolvem ao menos uma tendência. Em termos objetivos, somente em 
oitenta e sete (87) casos, ou seja, $10 \%$ do total, sendo setenta e um (71) no âmbito estadual e seis (6) nos governos locais, não foi mapeado nenhum descritor do protocolo de investigação. Por outro lado, o quantitativo de tendências varia de forma significativa em ambas esferas de governo. Enquanto nos municípios observa-se a média de 2,6 princípios/diretrizes por iniciativa, nos Estados esse número é de 2,45. Contudo, quando se analisa a presença de cada uma das tendências, é possível perceber nítidas diferenças, conforme Figura 1, que retrata a distribuição em todos os trabalhos, mas separados por esferas de governo.

Figura 1.Tendências Pós-Nova Gestão Pública, por Estados e municípios (2008-2016)

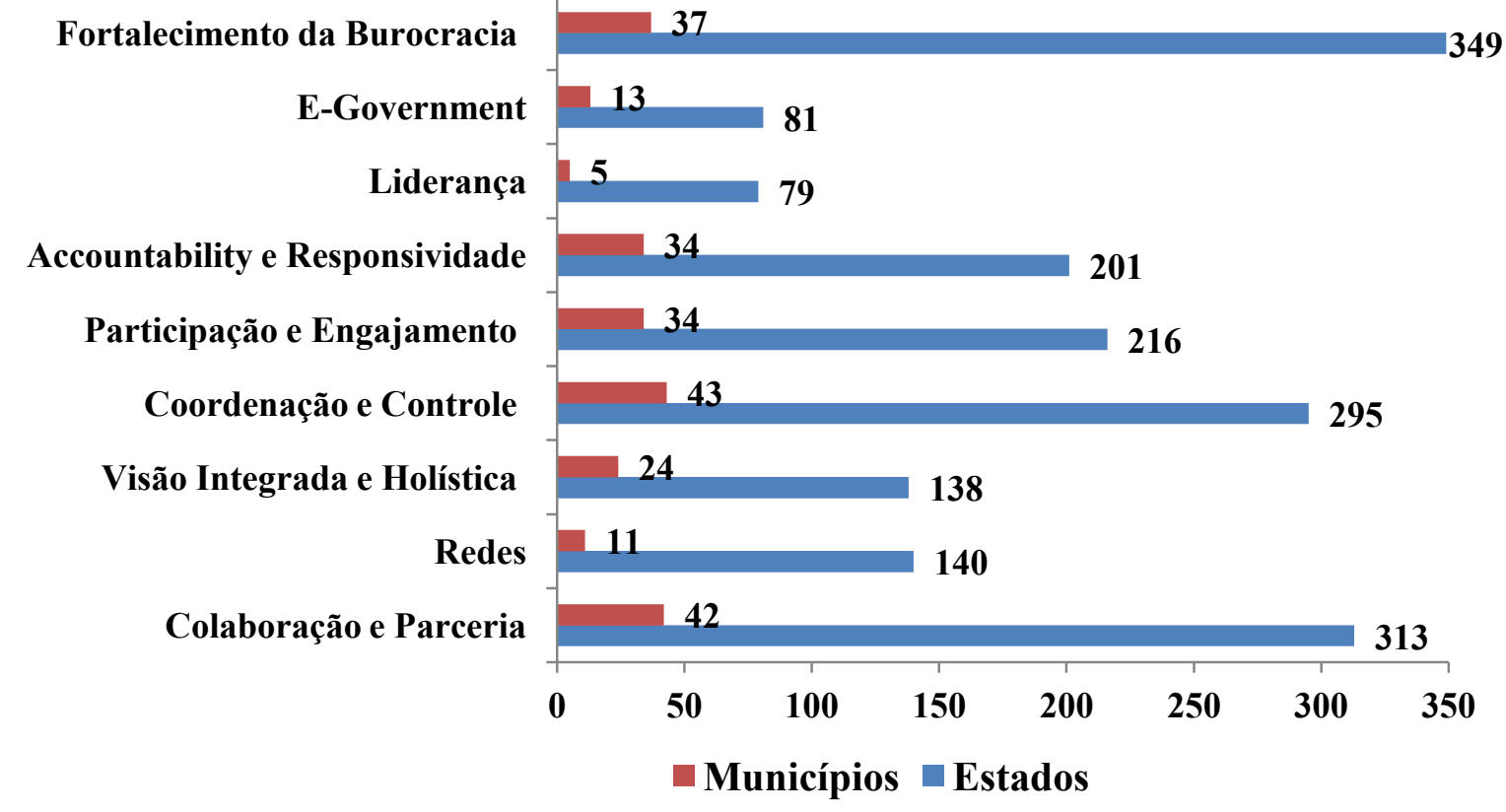

Fonte: Elaboração própria.

Proporcionalmente, chama à atenção a recorrência do fortalecimento da burocracia, colaboração/parceria e coordenação/controle em mais de $40 \%$ dos casos analisados. Um exemplo da primeira tendência pode ser observado no programa de desenvolvimento da gestão pública que foca em ações de capacitação de servidores de todas as municipalidades em técnicas avançadas de gestão (Almeida, Santos, \& Teles, 2014), enquanto que as ações de colaboração e parcerias podem ocorrer com diferentes configurações. Ou seja, inovações no rela- cionamento dentro do setor público, como a atuação de diversos órgãos na articulação de convênios entre o governo, os municípios do Estado do Rio de Janeiro e a associação da sociedade civil (Morais et al, 2014); e nas parcerias público-privadas na prestação de serviços, como o caso bem-sucedido de gestão do Hospital do Subúrbio na Bahia (Carreira, 2016). A presença dessas tendências é ainda bem semelhante quando divididas por esferas de governo. Em seguida, participação e engajamento (36\% e $29 \%$ ) e accountability/responsividade (36\% e $27 \%$ ) 
também demonstram o mesmo padrão de proximidade entre Estados e municípios, embora com menor frequência. Ainda com ocorrência significativa, vale destacar as tendências de visão integrada do governo e a atuação em redes. No outro extremo, contudo, os casos de e-government e trabalhos que envolvem questões relativas à liderança no setor público são menos comuns. Apesar de heterogêneo, os resultados indicam uma forte convergência das práticas de gestão nos governos subnacionais em relação às tendências identificadas na literatura pós-NGP, considerando os trabalhos apresentados nos congressos do Consad.
Quando se observa o recorte regional, somado às tendências mapeadas nos trabalhos que abordam ambas as esferas de governo (Quadro 2), é nítida a prevalência da Região Sudeste, com mais de $50 \%$ dos artigos, seguida pela Nordeste. Além disso, é possível perceber que são poucos os estudos que abordam mais de uma região e a presença dos princípios/diretrizes mais identificados (fortalecimento da burocracia, colaboração/ parceria e coordenação/controle) são ainda mais frequentes nos Estados do Sudeste.

Quadro 2.Frequência das Tendências, por Região do País

\begin{tabular}{|l|l|l|l|l|l|l|l|}
\hline & $\begin{array}{l}\text { Centro- } \\
- \text {-Oeste }\end{array}$ & Nordeste & Norte & Sudeste & Sul & $\begin{array}{l}\text { Mais de } \\
\text { uma região }\end{array}$ & Total \\
\hline Colaboração e parceria & 14 & 68 & 23 & 212 & 26 & 15 & 358 \\
\hline Visão integrada e holística & 9 & 27 & 9 & 103 & 11 & 3 & 162 \\
\hline Coordenação e controle & 18 & 64 & 22 & 201 & 28 & 5 & 338 \\
\hline Participação e engajamento & 12 & 49 & 28 & 129 & 24 & 11 & 253 \\
\hline Redes & 4 & 28 & 6 & 89 & 16 & 7 & 150 \\
\hline Accountability e responsividade & 11 & 47 & 20 & 127 & 21 & 10 & 236 \\
\hline E-government & 2 & 20 & 6 & 44 & 16 & 7 & 95 \\
\hline Liderança & 2 & 20 & 6 & 44 & 16 & 7 & 95 \\
\hline Fortalecimento da burocracia & 16 & 81 & 23 & 219 & 34 & 14 & 387 \\
\hline Total de trabalhos & 42 & 166 & 57 & 465 & 73 & 39 & 842 \\
\hline
\end{tabular}

Fonte: Elaboração própria.

Outra forma de analisar as relações entre as inovações nos governos estaduais e municipais e as diretrizes e princípios de gestão atuais é pelo recorte temporal. Notoriamente, a quantidade de trabalhos apresentados nos congressos do Consad varia bastante entre os anos. A Figura 2 a seguir procu- ra retratar em percentuais a ocorrência das tendências nos casos analisados durante os nove anos abordados neste artigo. A opção por porcentagem e não em valores absolutos visa a evitar vieses, dados os diferentes quantitativos de trabalhos durante os anos. 
Figura 2. Distribuição das Tendências Pós-Nova Gestão Pública, por ano

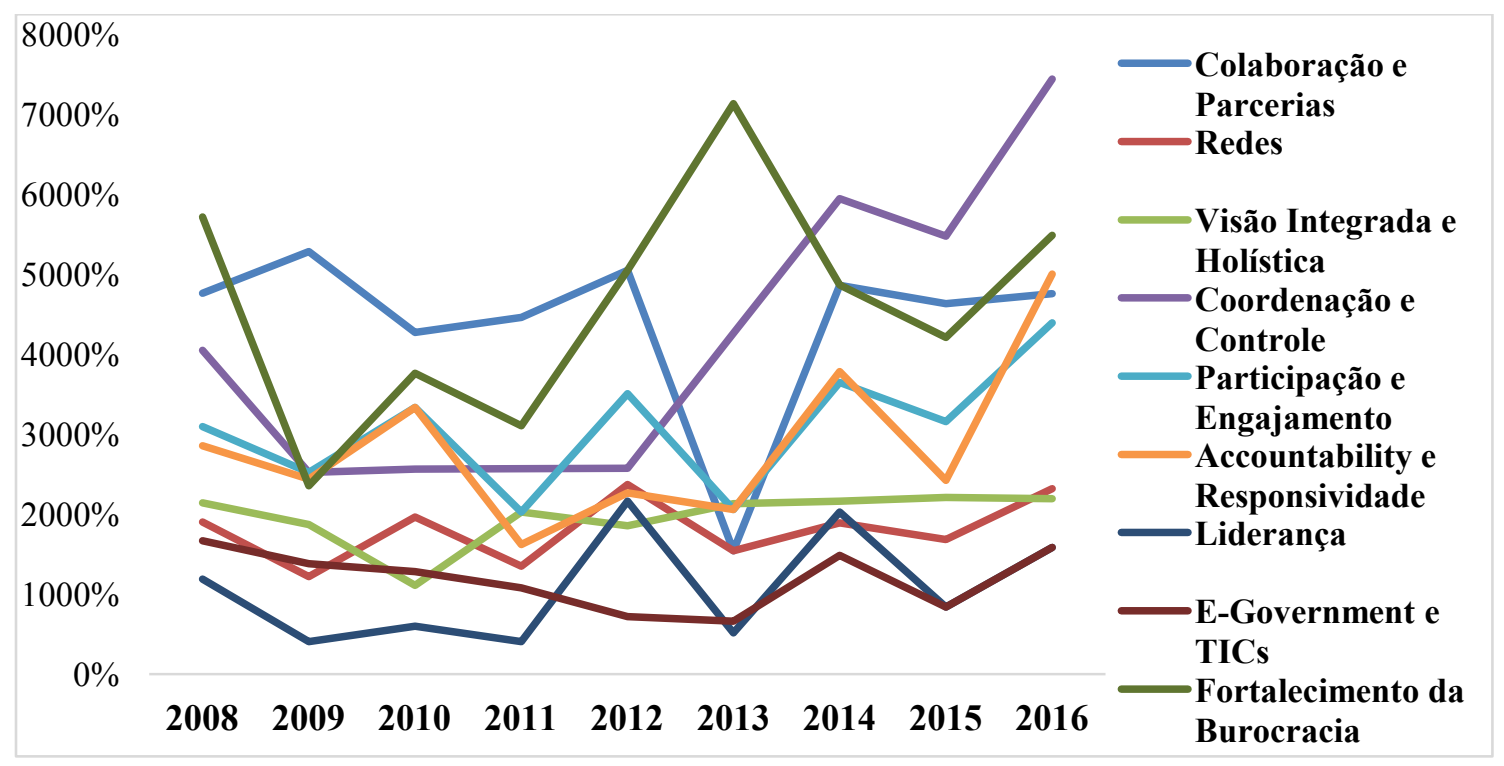

Fonte: Elaboração própria.

A despeito do fato do recorte temporal ser relativamente curto para traçar análises aprofundadas acerca do comportamento dos governos subnacionais, ao longo do tempo, alguns resultados são relevantes à luz da discussão de inovação na gestão pós-NGP. O primeiro deles está relacionado à volatidade nas frequências das tendências, que, majoritariamente, oscilam bastante. Segundo, coordenação e controle apresentam uma tendência crescente desde 2012, enquanto o fortalecimento da burocracia em alguns anos aparece como a tendência mais frequente. Nesse último caso, cabe destaque a experiência do governo de Minas Gerais de implantação de tutoria para promover o desenvolvimento gerencial e a formação de novas lideranças (Figueiredo e Neves, 2016).

Ademais, accountability e responsividade oscilam anualmente de forma mais acentuada, e liderança e participação/engajamento seguem a mesma lógica, embora de maneira um pouco mais parcimoniosa. Por fim, cabe destacar que e-government e visão integrada e holística, sobretudo a partir de 2014, demonstram mais estabilidade no decorrer do período em análise.

A última forma para compreender como as práticas da administração pública nos Estados e municípios brasileiros configuram-se nos anos recentes envolve a análise das eventuais convergências entre os princípios e as diretrizes de gestão. Em outras palavras, em que medida as experiências e os estudos relatados nos governos subnacionais incorporam mais de uma tendência e quais as frequências de coexistência entre elas. Conforme expectativa e em consonância com a perspectiva do pós-NGP como uma "cesta de compras" de diferentes métodos (Greve, et al. , 2016) e também do caráter multicausal e complexo das inovações em políticas públicas (Cavalcante, P., Camões, M., Cunha, B., \& Severo, W. ., 2017), o Quadro 3 expõe essas relações entre prin- 
cípios e diretrizes.

Os resultados não apenas confirmam esses pressupostos, como também exaltam a heterogeneidade nas composições das tendências. Isto é, embora os trabalhos e as iniciativas de gestão discutidas no congresso, em média, englobem mais de um princípio/ diretriz do pós-NGP, não necessariamente seguem o mesmo padrão de convergência de tendências. Obviamente, quanto maior a frequência das presenças nos trabalhos, maior tende a ser a interseção em relação às demais tendências.

Quadro 3.Convergência entre Tendências de Gestão

\begin{tabular}{|l|l|l|l|l|l|l|l|l|l|}
\hline & $\begin{array}{l}\text { Colabo- } \\
\text { ração e } \\
\text { parce- } \\
\text { rias }\end{array}$ & $\begin{array}{l}\text { Re- } \\
\text { des }\end{array}$ & $\begin{array}{l}\text { Visão } \\
\text { inte- } \\
\text { grada } \\
\text { e } \\
\text { holísti- } \\
\text { ca }\end{array}$ & $\begin{array}{l}\text { Coorde- } \\
\text { nação e } \\
\text { controle }\end{array}$ & $\begin{array}{l}\text { Partici- } \\
\text { pação e } \\
\text { engaja- } \\
\text { mento }\end{array}$ & $\begin{array}{l}\text { Account- } \\
\text { ability e } \\
\text { respon- } \\
\text { sividade }\end{array}$ & $\begin{array}{l}\text { Lider- } \\
\text { ança }\end{array}$ & $\begin{array}{l}\text { E-Gov- } \\
\text { ern- } \\
\text { ment }\end{array}$ & $\begin{array}{l}\text { Fortaleci- } \\
\text { mento da } \\
\text { burocra- } \\
\text { cia }\end{array}$ \\
\hline $\begin{array}{l}\text { Colaboração e } \\
\text { parcerias }\end{array}$ & 358 & 110 & 98 & 156 & 136 & 108 & 41 & 46 & 193 \\
\hline Redes & 110 & 150 & 50 & 69 & 61 & 53 & 16 & 19 & 82 \\
\hline $\begin{array}{l}\text { Visão integra- } \\
\text { da e holística }\end{array}$ & 98 & 50 & 162 & 95 & 62 & 54 & 20 & 22 & 86 \\
\hline $\begin{array}{l}\text { Coordenação e } \\
\text { controle }\end{array}$ & 156 & 69 & 95 & 338 & 109 & 122 & 41 & 39 & 179 \\
\hline $\begin{array}{l}\text { Participação e } \\
\text { engajamento }\end{array}$ & 136 & 61 & 62 & 109 & 253 & 128 & 29 & 58 & 107 \\
\hline $\begin{array}{l}\text { Accountability } \\
\text { e responsivi- } \\
\text { dade }\end{array}$ & 108 & 53 & 54 & 122 & 128 & 236 & 24 & 67 & 108 \\
\hline Liderança & 41 & 16 & 20 & 41 & 29 & 24 & 84 & 8 & 47 \\
\hline E-Government & 46 & 19 & 22 & 39 & 58 & 67 & 8 & 95 & 43 \\
\hline $\begin{array}{l}\text { Fortalecimento } \\
\text { da burocracia }\end{array}$ & 193 & 82 & 86 & 179 & 107 & 108 & 47 & 43 & 387 \\
\hline
\end{tabular}

A tendência mais comum nas iniciativas, fortalecimento da burocracia, parece bem alinhada com colaboração e parcerias e coordenação/controle. Isso sinaliza para a percepção do pós-NGP de que as ações governamentais tendem a não serem construídas isoladamente e serem fundamentadas na valorização de um quadro funcional, tanto profissionalizado quanto conectado.
Nota-se que a convergência com a liderança também é intensa, uma vez que 55\% dos trabalhos (47 de 84) que abordam essa tendência também relatam aspectos de valorização do corpo burocrático do governo, conforme o exemplo da iniciativa de Minas mencionada acima.

Em relação à coordenação e ao controle, 


\section{TENDÊNCIAS INOVADORAS DE GESTÃO NOS GOVERNOS SUBNACIONAIS BRASILEIROS}

conforme esperado, quase $50 \%$ dos casos envolvem colaboração intra e intergovernamental, como também interação com accountability e participação/engajamento. Seria razoável supor que a visão integrada e holística de governo e redes fossem convergentes com coordenação e controle, o que, de fato, se comprovou em aproximadamente $60 \%$ dos trabalhos que abordam aspectos relacionados à perspectiva de whole-of-government. A junção dessas duas tendências foi materializada nas iniciativas do Sistema Integrado de Gestão Administrativa (Siga) do governo do Espírito Santo que unificou informações de sete áreas essenciais, como compras e convênios (Margon et al, 2012); e também no caso do Escritório Central de Resultados em Processos do governo mineiro que coordena de forma integrada e transversal a gestão, um típico exemplo de monitoramento das organizações do Estado (Brito, Silveira, \& Ferreira, 2014).

Do mesmo modo, é muito frequente e compreensível a presença do princípio de parcerias nas inovações, que se fundamenta na constituição de redes, o que se comprova em aproximadamente $75 \%$ dos casos analisados. Não necessariamente toda colaboração constitui rede, mas o contrário é predominante, como nos exemplos da Rede de Capacitação, construída em parceria entre a Escola de Governo do Paraná e seis Instituições Públicas de Ensino Superior (Machado \& Muller, 2010); e da Rede de Consultores Internos que disseminam tecnologias atuais de gestão nos órgãos do governo da Bahia (Carvalho, 2012).

Quanto à participação e ao engajamento, a despeito de ser um princípio/diretriz que remete também à evolução do movimento gerencial , a sua presença na prática administrativa dos governos brasileiros continua representativa. Nesse sentido, observa-se forte relacionamento com as tendências mais frequentes, como também é bastante convergente com e-government e accountability, uma vez que $60 \%$ e $55 \%$, respectivamente, possuem interface com participação nas políticas públicas e de gestão discutidas nos trabalhos do congresso Consad. Essa combinação de tendências é materializada em experiência como a central do cidadão, que propicia formas de interferência e fiscalização direta da sociedade, novas ferramentas de controle social e interação e apresentação das informações aos cidadãos do Rio Grande do Sul (Foernges e Lopes, 2014). Ademais, no âmbito local, o caso do portal de licitações dos municípios no Ceará também constitui uma inovação que possibilita aumentar a participação social, dar condições para controle e responsividade aos gestores e transparência por meio de uma estratégia de e-government (Pinheiro \& Melo, 2016).

\section{CONSIDERAÇÕES FINAIS}

Diante das constantes e profundas transformações de diferentes naturezas pelas quais o setor público vem passando nas últimas décadas, as políticas públicas e de gestão também se modificaram significativamente nesse período. Após inúmeros esforços de reformar a administração pública pelo mundo, atualmente prevalece um relativo consenso de que o caminho mais efetivo para compreender a configuração e o funcionamento dos governos é analisar instrumentos/ ferramentas de gestão, muitas vezes considerados como graduais e constantes 
melhorias (micro-improvements) ou inovações (Christensen \& Lægreid, 2007; Pollit \& Buckaert, 2011; Greve, et al. , 2016).

Justamente para contribuir com essa importante temática, este artigo propôs-se a abordar, de forma exploratória e descritiva, como se configuram as práticas de gestão nos governos estaduais e municipais pelo Brasil. Para tanto, em vez de analisar casos específicos de reformas administrativas, opta-se em identificar a presença ou não de tendências, em termos de princípios e diretrizes, identificadas na literatura acadêmica internacional como pertencentes ao que se convém denominar de pós-NGP. Do ponto de vista metodológico, as fontes de informações são as políticas públicas e de gestão dos governos subnacionais apresentadas nos trabalhos das nove edições do Congresso do Conselho Nacional de Secretários de Estado da Administração (Consad). Foi elaborada uma base de dados a partir do protocolo e da análise de conteúdo em mais de oitocentos (800) estudos com vistas a identificar as tendências de gestão pós-NGP na prática da administração contemporânea nos governos subnacionais no Brasil. Cabe ressaltar que essa estratégia analítica, obviamente, traz limitações à validade externa da pesquisa, ou seja, capacidade de generalização dos resultados para toda a administração pública subnacional no país.

As análises empíricas, entretanto, trazem achados que merecem atenção. Embora sejam notórias as dificuldades de caráter legal, econômico e até mesmo cultural dessas esferas de governo (Abrucio, 2005; Grin \& Abrucio, 2016), as práticas de gestão recentes indicam alta convergência com o que está sendo implementado nos países desenvolvidos.

Se, por um lado, prevalece ampla heterogeneidade das tendências pós-NGP que varia tanto nos governos estaduais quanto nos municipais, por outro observa-se certa uniformidade no fato de que a grande maioria das iniciativas se fundamentam não somente em um princípio/diretriz, mas em vários, sendo a média, próxima a 2,5 tendências, em ambas as esferas. Logo, confirma-se a premissa de complexidade e coexistência de tendências, bem como os resultados indicam a perspectiva contemporânea de gestão de que as políticas inovadoras advêm de escoIhas e implementação, baseadas em "cesta de compras" de diferentes métodos (Greve, et al. , 2016). Finalmente, cabe mencionar que, em relação à dimensão temporal, os resultados sinalizam volatilidade nas frequências das tendências, bastante oscilantes.

Embora interessantes, é preciso ponderar algumas limitações metodológicas. A primeira é que a ausência de informações e/ou de relatórios sistematizados de experiências de gestão ou de inovação disponível, como existiam na vigência do Prêmio de Gestão e Cidadania (Jacobi \& Pinho, 2006). Isto obriga os pesquisadores a optar por estudos mesmo acadêmicos, que abordem as iniciativas no âmbito subnacional. Além disso, é natural que as análises foquem, predominantemente, em experiências exitosas, que costumam ser chamadas de campeãs ou de boas práticas, o que, necessariamente, não é algo negativo, haja vista que ressaltam justamente aquelas iniciativas mais relevantes, com características inovadoras e com potencial de difusão. Vale salientar que a opção por trabalhos do Consad, devido a sua diversidade 
de abordagens e limitações à generalização dos resultados, apresenta restrições. Não obstante, trata-se do principal encontro do campo e, sem dúvida, a maior fonte de práticas da gestão pública subnacional no país. $\mathrm{E}$, por isso, como toda estratégia científica possui prós e contras que os pesquisdores precisam enfrentar e ponderar no decorrer dos estudos.

Quanto à agenda futura, essa pesquisa sinaliza para um terreno fértil que pode expandir as análises para outros congressos de destaque no campo. Estratégias qualitativas podem abordar outras dimensões das inovações nos governos subnacionais, tais como barreiras, indutores, tipos, dentre outras, que ajudam a compreender os processos de implementação desse fenômeno tão complexo e ainda pouco explorado na administração pública brasileira. Além disso, outros focos de estudos podem voltar-se para a análise de novas estratégias de gestão que valorizem as diversas formas de parcerias público-privadas, bem como avaliar em que medida a deterioração econômica e social recente no país tem impactado $o$ funcionamento da gestão pública estadual e municipal.

\section{REFERÊNCIAS}

Abrucio, F. L. (2005). Reforma do Estado no federalismo brasileiro: A situação das administrações públicas estaduais. Revista de Administração Pública-RAP, 39(2), 401-419.

Abrucio, F. L. (2007). Recent trajectory of the Brazilian public management: A critical assessment and the renewal of the reform agenda. Revista de Administração Pública, 41(SPE), 67-86. https://dx.doi.org/10.1590/

\section{S0034-76122007000700005}

Alverga, C. F. (2014). Levantamento teórico sobre as causas dos insucessos das tentativas de reforma administrativa. Revista Do Serviço Público, 54(3), 29-46. Recuperado de https://doi.org/10.21874/rsp.v54i3.270

Bresser-Pereira, L. C. (2002). Reforma da nova gestão pública: Agora na agenda da América Latina, no entanto. Revista do Serviço Público. 53(1), 5. https://doi.org/10.21874/ rsp.v53i1.278

Bresser-Pereira, L. C.; \& Pacheco, R. A (2005). Reforma do Estado e o Desenvolvimento. Revista Eletrônica Sobre Reforma do Estado, 3, 151-170.

Brulon, V., Ohayon, P., \& Rosenberg, G. (2012). A reforma gerencial brasileira em questão: Contribuições para um projeto em construção. Revista do Serviço Público, 63(3), 265-284. http://seer.enap.gov.br/index.php/RSP/article/view/99/95

Cavalcante, P. (2017). Gestão pública contemporânea: do movimento gerencialista ao pós-NPM (No. 2319). Texto para Discussão. (IPEA), 2319(1),1-40. http://hdl.handle. net/10419/177535

Cavalcante, P., \& Camões, M. (2017). Do the Brazilian innovations in public management constitute a new model? RAI Revista de Administração e Inovação, 14(1), 90-96. Recuperado de http://www.revistas.usp.br/rai/article/view/107563

Cavalcante, P., \& Carvalho, P. (2017). Profissionalização da burocracia federal brasileira (1995-2014): Avanços e dilemas. Revista de 
Administração Pública, 51(1), 1-26. https:// dx.doi.org/10.1590/0034-7612144002

Cavalcante, P., Camões, M., Cunha, B., \& Severo, W. (2017). Inovação no setor público: Teoria, tendências e casos no Brasil. Brasília; Enap: Ipea,

Christensen, T., \& Lægreid, P. (2007). The whole-of-government approach to public sector reform. Public administration review, 67(6), 1059-1066. https://doi.org/10.1111/ j.1540-6210.2007.00797.x

Comissão Europeia. Powering European Public Sector Innovation: Towards a New Architecture. Report of the Expert Group on Public Sector Innovation, Directorate General for Research and Innovation, Innovation Union, European Commission, Brussels, 2013.

Corrêa, I. M. (2007). Planejamento estratégico e gestão pública por resultados no processo de reforma administrativa do estado de Minas Gerais. Revista de Administração Pública, 41(3), 487-504. https://dx.doi. org/10.1590/S0034-76122007000300006

Costa, F. L. D. (2008). Brasil: 200 anos de Estado; 200 anos de administração pública; 200 anos de reformas. Revista de Administração Pública-RAP, 42(5), 2008. https://dx.doi. org/10.1590/S0034-76122008000500003

Paula, A. P. P. de. (2005). Por uma nova gestão pública: limites e potencialidades da experiência contemporânea. FGV Editora.

Paula, A. P. P.de., \& Keinert, T. M. M. (2016). Inovações institucionais participativas: Uma abordagem exploratória da produ- ção brasileira em administração pública na RAP e no EnAPG (1990-2014). Cadernos Ebape. $\mathrm{Br}, 14(3)$, 744-758. https://dx.doi. org/10.1590/1679-395130829

Farah, M. F. S. (2008). Disseminação de inovações e políticas públicas e espaço local. Organizações \& Sociedade, 15(45), 107-126. Available from http://www.scielo.br/ scielo.php?script=sci_arttext\&pid=S1984-92302008000200009\&lng=en\&nrm=iso . access on 27 Nov. 2019.

Gaetani, F. (2003). O recorrente apelo das reformas gerenciais: uma breve comparação. Revista Do Serviço Público, 54(4), p. 23-43. https://doi.org/10.21874/rsp.v54i4.274

Greve, C., Lægreid, P., \& Rykkja, L. H. (Eds.). (2016). Nordic administrative reforms: Lessons for public management. London, UK: Macmillan/Palgrave. https://doi. org/10.1057/978-1-137-56363-7

Grin, E. J., \& Abrucio, F. L. (2016) Facetas del federalismo en Brasil: Descentralización, recentralización y los desafíos de la cooperación intergubernamental. Revista Iberoamericana de Gobierno Local, (11), 1-39.

Jacobi, P. R., \& Pinho, J. A. (2006). Inovação no campo da gestão pública local: Novos desafios, novos patamares. Rio de Janeiro. FGV Editora.204.

Lotufo, M., \& de Miranda, A. S. (2007). Sistemas de direção e práticas de gestão governamental em secretarias estaduais de Saúde. Revista de Administração Pública, 41(6), 1143-1163. ISSN: 0034-7612. Disponível em: https://www.redalyc.org/articulo. oa? id=2410/241016440007 


\section{TENDÊNCIAS INOVADORAS DE GESTÃO NOS GOVERNOS SUBNACIONAIS BRASILEIROS}

Marini Ferreira, C. M. (2005). Aspectos contemporâneos do debate sobre reforma da administração pública no Brasil: A agenda herdada e as novas perspectivas. Revista Eletrônica Sobre Reforma do Estado, (1).

Osborne, S.; Brown, K. Managing change and innovation in public service organizations. Oxon: Routledge, 2005. https://doi. org/10.4324/9780203391129

Raupp, Fabiano Maury, \& Pinho, José Antonio Gomes de. (2011). Construindo a accountability em portais eletrônicos de câmaras municipais: um estudo de caso em Santa Catarina. Cadernos EBAPE.BR, 9(1), 116-138. https://dx.doi.org/10.1590/S167939512011000100008

Spink, P. K. (2006). A inovação na perspectiva dos inovadores. In: Jacobi, P. R., \& Pinho, J. A. (2006). Inovação no campo da gestão pública local: Novos desafios, novos patamares. FGV Editora.ISBN 85-225-0540-3

\section{Referências dos Casos}

Almeida, D. M., Santos, F. M. L. N., \& Teles, F. M. C. (2014). Programa de desenvolvimento da gestão pública para municípios (PRODEG-M): A intersetorialidade como estratégia na formação dos servidores públicos municipais no Ceará. VII Congresso CONSAD de Gestão Pública.

Brito, A.; Silveira, M. C.; Ferreira, V. C. (2014). Dez anos da gestão de processos no governo de Minas Gerais: A evolução rumo à estruturação do escritório central de resultados em processos-alinhando estratégia e processos. VII Congresso CONSAD de
Gestão Pública.

Carrera, M. Parceria (2016) Público-Privada em saúde: Os resultados do Hospital do Subúrbio (Salvador-Bahia). IX Congresso CONSAD de Gestão Pública.

Carvalho, R. (2012) Rede de consultores internos do estado da Bahia (RCl-BA): Instrumento de aumento da governança da máquina pública estadual. $V$ Congresso CONSAD de Gestão Pública.

Figueiredo, R., \& Neves, F. (2015). Formando novas lideranças: a experiência de Minas Gerais na implantação de um programa de tutoria. Congresso CONSAD de Gestão Pública.

Foernges, J, \& Lopes, K. (2014) A Central do Cidadão: a transparência como fomento ao controle social. VII Congresso CONSAD de Gestão Pública.

Machado, H. V., \& Muller, C. C. (2010) Redes de capacitação: A experiência da Escola de Governo e das Universidades Públicas do Estado do Paraná. III Congresso CONSAD de Gestão Pública.

Margon, D. G., Aliguieri, J. S., Casagrande, M. L., Vervloet, V.C. (2012) Sistema integrado de gestão administrativa do governo do estado do Espírito Santo. $V$ Congresso CONSAD de Gestão Pública.

Morais, L. D. S., Oliveira, R. R., Lage, T. C., \& Nascimento, V. M. S. D. (2014). Convênios no Rio de Janeiro: articulações entre estados, municípios e sociedade civil com aprendizagens in loco. VII Congresso CONSAD de Gestão Pública. 
Pedro Luiz Costa Cavalcante

Pinheiro, A, \& Melo, T. (2016) O portal de licido princípio da transparência. IX Congresso tações dos municípios do TCM/CE sob a luz 